\title{
Minireview
}

Clinical

Practice

\section{Orphan Kidney Diseases}

\author{
Neveen A. Soliman \\ Center of Pediatric Nephrology and Transplantation, Department of Pediatrics, Kasr Al Ainy School of Medicine, \\ Cairo University, Egyptian Group for Orphan Renal Diseases (EGORD), Cairo, Egypt
}

\begin{abstract}
Key Words
Rare diseases - Monogenic kidney diseases - Molecular genetics · Nephronophthisis · Ciliopathies · Genetic nephrotic syndrome $\cdot$ Podocytopathies
\end{abstract}

\begin{abstract}
Rare kidney diseases are a unique subset of renal disorders that are often termed 'orphan' as a result of a multitude of reasons: the small number of patients with the consequent lack of well-defined natural history and course of many of these diseases, limited awareness among the medical community, and finally the significant cost of developing novel therapeutics which makes many of these diseases unattractive targets for the pharmaceutical industry. Nevertheless, in the last decade the study and clinical management of rare kidney disease patients has been the focus of many investigative efforts. In recent years we have witnessed an enormous expansion in our knowledge of the genetic nature of a number of rare kidney diseases. Moreover, the investigation of the role of genetic disruption aiming at elucidating the pathogenesis of different and complex renal diseases has helped not only in understanding the disease states, but has also given us fundamental insights into a number of kidney developmental and physiological functions. This article will give an overview of orphan renal diseases with particular emphasis on monogenic kidney diseases. It will also focus on the classification of these diseases while highlighting a prominent example in each category.
\end{abstract}

Copyright $\odot 2012$ S. Karger AG, Basel
(C) 2012 S. Karger AG, Basel

$1660-2110 / 12 / 1204-0194 \$ 38.00 / 0$

Fax +4161306 1234

E-Mail karger@karger.ch

www.karger.com
Accessible online at: www.karger.com/nec

\section{Introduction and Definitions}

'Orphan' is used interchangeably with 'rare' to describe a subset of kidney diseases with a particularly low prevalence, defined by the National Institutes of Health Office of Rare Diseases Research (rarediseases.info.nih. gov) as any condition that affects fewer than 200,000 people in the United States. On the other hand, the European Union considers diseases to be rare when they affect not more than 5 per 10,000 persons $(<1$ person per 2,000) [1].

Since many of these diseases are complex and have genetic or metabolic causes, only a few physicians are aware of them, whereas the majority are unlikely to have the necessary experience to diagnose such diseases or offer treatment, hence the delay in diagnosis and therapy. Given that a high proportion of rare kidney diseases have a genetic background, they are often first expressed in childhood with an enormous psychological and physical burden for the affected patients and their families.

\section{Genetic Kidney Diseases}

Renal injury with a monogenic cause represents only a small fraction of the total spectrum of renal diseases. The most common types of renal disease are the result of a complex interplay between multiple genetic and envi-

Neveen A. Soliman

Department of Pediatrics, Center of Pediatric Nephrology and Transplantation Kasr Al Ainy School of Medicine, Cairo University 99 El-Manial Street, Cairo 11451 (Egypt)

E-Mail nsoliman@kasralainy.edu.eg 
ronmental factors, hence the name polygenic kidney diseases.

Single-gene disorders are rare, strongly affect the disease phenotype, manifest early in life, are seldom associated with environmental effects, and are usually detected by linkage mapping. On the other hand, polygenic disorders are more common, exert weak causality on the disease phenotype, manifest later in life, are commonly associated with environmental effects, and are usually detected by genome-wide association studies [2].

Renal diseases are well represented on the list of rare diseases, and according to the current estimates, include over 100 disorders of transport, development, metabolism, and inflammation [3]. The small patient populations with phenotypic variability imply limited knowledge of the natural course which is all too often difficult to define, lack of standardization of diagnostic procedures and fragmentation of the clinical and biological data collections, and comprise small cohorts restricting the power of clinical studies $[4,5]$. This renders comprehensive care particularly challenging due to frequently hidden comorbidities.

Gained knowledge from the fascinating area of research in molecular genetics is immensely and rapidly growing - perhaps more than any other field in medicine. This knowledge will eventually have great clinical impact in terms of elucidating the pathogenesis of variable and complex renal diseases. Having said that, only little progress has been made towards improved diagnosis and therapy of these conditions. The challenge then becomes how this information can be integrated and used for the benefit of patients, their families, and all individuals at risk of developing CKD [6].

\section{Benefits of Rare Renal Diseases as a Research Priority}

A commonly asked question amongst the medical community is why should we focus on rare kidney diseases as a research priority when they are by no means a public health challenge? It is believed that investigative efforts into this unique research area would allow mining a wealth of novel information and knowledge resulting in: (1) unraveling and understanding the underlying genetic defect, and (2) elucidating underlying pathogenetic mechanisms and expanding our knowledge with fundamental insight into many of the renal developmental and physiological functions. This gained knowledge would undoubtedly pave the way to potential development of novel targeted 'mechanism-based' therapeutics, not only for rare kidney diseases, but hopefully for more common renal illnesses as well.

\section{Classification}

Numerous classifications of inherited kidney diseases have been proposed, e.g. monogenic versus polygenic, glomerular versus tubular, and structural versus functional disorders.

Genetic disorders of renal growth and structure result in a reduced number of nephrons and/or an abnormal patterning and cellular organization of the renal tissue, e.g. polycystic kidney disease and nephronophthisis(NPHP; early onset/autosomal recessive) medullary cystic kidney diseases complex (late onset/ autosomal dominant). In contrast, disorders of renal function result in derangement of one of the basic kidney functions, whether glomerular or tubular, that clinically leads to the development of various renal diseases, e.g. nephrotic syndrome and inherited podocyte disease (table 1).

Inherited disorders of renal structure and function are relatively common causes of end-stage renal disease (ESRD) requiring renal replacement therapy. These represent the fifth most common cause of ESRD after diabetes, hypertension, glomerulonephritis, and pyelonephritis, respectively, with an annual incidence of at least $10 \%$ $[7,8]$.

\section{Genetic Disorders of Renal Growth and Structure}

Perhaps the most pronounced examples in this category are the cystic diseases of the kidney, which are significant contributors to renal malformations and common causes of ESRD. These encompass a number of disorders that range from conditions in which the kidney is either the sole organ affected (isolated NPHP), to pleiotropic syndromes where cystic kidney formation is but one of the observed pathologies with extrarenal involvement (NPHP-associated ciliopathies). The most frequent extrarenal involvement is retinal degeneration, in addition to cerebellar vermis hypoplasia (Joubert syndrome), occipital encephalocele (Meckel-Gruber syndrome), hepatic fibrosis, situs inversus, bronchiectasis, and skeletal defects.

Interestingly, an extensive body of data fueled by a combination of mutation identification in humans and studies in animal models suggests a common thread, 
Table 1. Genetic structural and functional renal diseases

I. Genetic disorders of renal growth and structure

Ciliopathies

ADPKD, types 1 and $2^{1}$

ARPKD

NPHP types 1-11

Medullary cystic kidney disease

Joubert syndrome-related disorders

Meckel-Gruber syndrome

Bardet-Biedl syndrome types 1-12

Alström syndrome

Sensenbrenner syndrome (cranioectodermal dysplasia)

Oral-facial-digital syndrome 1

Ivemark syndrome

Short rib-polydactyly syndromes (Jeune syndrome/

asphyxiating thoracic dystrophy)

Ellis-van Creveld syndrome

Congenital abnormalities of the kidney and urinary tract

Renal agenesis

Renal hypoplasia/dysplasia syndrome

Multicystic renal dysplasia

Vesicoureteral reflux

Branchio-oto-renal syndrome

Fraser syndrome

Hypoparathyroidism, deafness, renal syndrome

Kallman syndrome

Renal coloboma syndrome

Renal cysts and diabetes syndrome

Split-hand/split-foot malformation

Townes-Brocks syndrome
II. Genetic disorders of renal function

Glomerular diseases

Congenital SRNS (Finnish type)

SRNS types 2, 3, and 4

Pierson syndrome

SRNS, adult-onset

Denys-Drash syndrome, Frasier syndrome

Nail-Patella syndrome

Mitochondrial disorders with SRNS

Lysosomal disorders with SRNS

Alport syndrome (XL, AR, AD)

Alport syndrome with leiomyomatosis

Schimke immuno-osseous dystrophy

Familial amyloidosis

Renal tubular diseases and metabolic diseases

Renal glucosuria

Aminoacidurias

Proximal renal tubular acidosis

Hypophosphatemic rickets

Cystinosis

Lowe syndrome

Bartter syndrome types 1-4

Gitelman syndrome

Liddle syndrome

Gordon syndrome

Pseudohypoaldosteronism types 1 and 2

SeSAME syndrome

Distal renal tubular acidosis

Diabetes insipidus, nephrogenic

Fabry disease

Nephrolithiasis

Cystinuria - dent disease - lysinuric protein intolerance

Primary hyperoxaluria type 1,2, and 3

Adenine-phosphoribosyl-transferase deficiency

Xanthinuria - distal renal tubular acidosis

$\mathrm{ADPKD}=$ Autosomal dominant polycystic kidney disease; $\mathrm{ARPKD}=$ autosomal recessive polycystic kidney disease; $\mathrm{AD}=$ autosomal dominant; $\mathrm{AR}=$ autosomal recessive; NPHP = nephronophthisis; SRNS = steroid resistant nephrotic syndrome; SeSAME = seizures, sensorineural deafness, ataxia, mental retardation, and electronic imbalance. ${ }^{1}$ Not a rare disease, mostly of late onset.

where virtually all known renal cystic disease-associated genes encode proteins necessary for aspects of ciliary function $[9,10]$. Expanding from that observation, it is now becoming apparent that most - if not all - disorders of the cilium have a cystogenic component, which in turn has placed kidney cyst formation as a hallmark feature of the ciliopathies. There is a rapidly growing list of diseases associated with ciliary dysfunction $[11,12]$.

NPHP is an autosomal recessive cystic kidney disease that constitutes the most frequent genetic cause for endstage kidney disease (ESKD) in the first three decades of life. The prevalence in a population of childhood ESKD is estimated at 5\% [13]. NPHP and associated ciliopathies had been reported in many countries worldwide [14-16]. In addition to this apparent variability in the spectrum and severity of phenotype, NPHP is genetically heterogenous. To date, mutations have been identified in 13 different genes (NPHP1-11, NPHP1L, and TTC21B) which altogether account for approximately $30 \%$ of patients $[17,18]$. The protein products of all of these genes localize on primary cilia and related structures (basal bodies, centrosomes). The disease can be subdivided clinically based on the age of onset of ESKD into infantile, juvenile, and adolescent categories with a 
median age of onset of 1,13 , and 19 years of age, respectively [19].

Remarkable progress has been made, and is still ongoing, towards gaining an understanding of the genetic, cellular, and molecular basis of the ciliopathies/cystic diseases of the kidney. Undoubtedly, this will give us more insight into disease mechanisms, explain clinical heterogeneity, and facilitate exploring novel therapeutic venues with an increasing level of efficacy and specificity [11]. Increased understanding of ciliary biology will improve the diagnosis and management of NPHP and NPHP-associated ciliopathies $[20,21]$.

\section{Genetic Disorders of Renal Function}

Approximately $10-20 \%$ of children and $40 \%$ of adult nephrotic syndrome patients are steroid resistant (SRNS); they are therefore at higher risk of reaching ESKD. SRNS typically manifests histologically as focal segmental glomerulosclerosis, a lesion characterized by sclerosis and podocyte foot process effacement in some of the glomeruli and a part of each entire glomerulus $[22,23]$.

It has clearly been shown that inherited structural defects of the glomerular filtration barrier are responsible for a large proportion of SRNS. Genetic studies have identified several genes involved in the development of SRNS, whether autosomal recessive (NPHS1, NPHS2, PLCE1, CD2AP, LAMB2, ITGB4, SCARB2, COQ2, PDDS2, $M T T L 1$, and recently COQ6 and MYO1E), or autosomal dominant/complex inheritance (TRPC6, ACTN4, WT1, INF2, LMX1B, SMARCAL1) [24-26]. These breakthrough findings clearly emphasized the pivotal role of the podocyte in the GBM integrity, hence playing a crucial role in the pathogenesis of glomerulopathies.

Algorithms for appropriate mutational screening for SRNS has recently been proposed with a systematic stepwise approach based on: (1) age at onset, (2) familial/sporadic status, (3) type of renal histopathological findings, and (4) presence of extrarenal abnormalities [24-27]. Of interest, in a Spanish cohort of 125 patients belonging to 110 families, mutations were detected in $100 \%$ of congenital onset, $57 \%$ of infantile onset, 24 and $36 \%$ of early and late childhood-onset, 25\% of adolescent-onset, and $14 \%$ of adult-onset patients. The most frequently mutated gene was NPHS1 in congenital onset and NPHS2 in the other groups [28]. In adult-onset cases, screening for p.R229Q in the NPHS2 gene is recommended, with analysis of the whole gene if positive. TRPC6 and INF2 testing is indicated only for autosomal dominant late-onset familial focal segmental glomerulosclerosis, with ACTN4 analysis if negative $[28,29]$.

Unraveling the underlying genetic defect in SRNS modifies the approach taken to counsel the patients regarding immunosuppressive therapy and the risk of recurrence after renal transplantation since hereditary podocytopathies are associated with poorer renal outcome than the nongenetic variants as they show no or only little response to immunosuppressive agents [30]. Overall, genetic testing of podocyte genes should be considered a diagnostic tool in both pediatric and adult SRNS patients as the identification of a genetic origin of the disease may allow the specification of the prospective clinical course and may, therefore, have a direct implication on therapy regimen and family counseling [31].

\section{Orphan Kidney Disease Bodies}

Nowadays, it is crucial more than ever to establish registries for rare kidney diseases. This enables investigators to study phenotypic characteristics/variability and genotype phenotype correlation in a larger number patients from multiple centers/countries, thereby avoiding fragmentation of data collection and small cohorts that restrict the power of such studies. Examples include the Cure Cystinosis International Registry (cystinosis, https://cystinosis.patientcrossroads.org), European Hyperoxaluria Consortium OxalEurope (primary hyperoxaluria, http://www.oxaleurope.org), PodoNet (podocytopathies, http://www.podonet.org/opencms/opencms/ podonet/podonet_en/home), etc.

Medical information resources and portals were also established and continue to be regularly updated to assist researchers, health care providers, and patients and their families, e.g. National Institute of Health Office of Rare Diseases Research (http://rarediseases.info.nih.gov), Orphanet (www.orpha.net), National Organization for Rare Diseases (NORD; http://www.rarediseases.org), GeneTests (http://www.ncbi.nlm.nih.gov/sites/GeneTests), etc.

Networks and groups aiming to study causes, pathogenetic mechanisms, and consequences of rare kidney diseases, as well as promoting international collaboration to maximize the gains while avoiding duplication of efforts constitute a step in the right direction. Examples include the ERA-EDTA Working Group on Inherited Kidney Disorders (WGIKD; http://www.era-edta.org/ wgikd/ERA-EDTA_working_group_on_Inherited_kidney_disorders.htm) and the European Network for the Study of Orphan Nephropathies (EUNEFRON; http:// www.eunefron.org). 
Moreover, the FDA Office of Orphan Products Development provides incentives for sponsors to develop products for rare diseases and advances the evaluation and development of products (drugs, biologics, devices, or medical foods) that demonstrate promise for the diagnosis and/or treatment of rare diseases (http://www.fda.gov/ ForIndustry/DevelopingProductsforRareDiseasesConditions/default.htm).

\section{Conclusion}

Although the care for patients with rare kidney diseases is frequently hampered by a multitude of diagnostic and therapeutic hurdles, it should not be viewed as insur- mountable given the compelling medical and ethical reasons to address their needs. It remains essential to promote awareness of orphan kidney diseases and to better train nephrologists (and non-nephrologists) to recognize the clinical features of rare kidney disorders, use adequate diagnostic tools, and timely refer afflicted patients to expert centers. Unraveling the genetic basis of many of these diseases continues and will ultimately provide novel genetic risk factors to guide targeted interventional treatment and pharmacological therapeutics to stop or at least retard disease progression. The challenges of the future will be to translate the increasing molecular knowledge learnt into the understanding of, and yielding new insights relevant to, acquired more frequent disorders.

\section{References}

1 Van Weely S, Leufkens HG: Priority medicines for Europe and the world - a public health approach to innovation; in Kaplan W, Laing R (eds): Orphan Diseases. Geneva, World Health Organization, 2004, pp 95100.

2 Altshuler D, Daly MJ, Lander ES: Genetic mapping in human disease. Science 2008; 322:881-888

-3 Shayman JA: Thinking about rare kidney diseases. J Am Soc Nephrol 2006;17:15-16.

4 Watson MS, Epstein C, Howell RR, Jones MC, Korf BR, McCabe ER, Simpson JL: Developing a national collaborative study system for rare genetic diseases. Genet Med 2008; 10:325-329.

5 Willnow TE, Antignac C, Brändli AW, et al: The European Renal Genome Project: an integrated approach towards understanding the genetics of kidney development and disease. Organogenesis 2005;2:42-47.

6 Laberge AM, Burke W: Clinical and public health implications of emerging genetic technologies. Semin Nephrol 2010;30:185194.

7 United States Renal Data System. 2009. (www.usrds.org).

8 UK Renal Registry Report. 2009. www. renalreg.com.

9 Hildebrandt F, Otto E: Cilia and centrosomes: a unifying pathogenic concept for cystic kidney disease? Nat Rev Genet 2005;6: 928-940.

10 Watnick T, Germino G: From cilia to cyst. Nat Genet 2003;34:355-356.

- 11 Badano JL, Mitsuma N, Beales PL, Katsanis $\mathrm{N}$ : The ciliopathies: an emerging class of human genetic disorders. Annu Rev Genomics Hum Genet 2006; 7:125-148.
12 Fliegauf M, Benzing T, Omran H: When cilia go bad: cilia defects and ciliopathies. Nat Rev Mol Cell Biol 2007;8:880-893.

13 Hildebrandt F, Zhou W: Nephronophthisisassociated ciliopathies. J Am Soc Nephrol 2007;18:1855-1871.

14 Soliman NA, Hildebrandt F, Allen SJ, Otto EA, Nabhan MM, Badr AM: Homozygous NPHP1 deletions in Egyptian children with nephronophthisis including an infantile onset patient. Pediatr Nephrol 2010;25:21932194.

15 Ashizawa M, Miyazaki M, Furusu A, Abe K, Kanamoto Y, Iwanaga N, Ozono Y, Harada T, Taguchi T, Kohno S: Nephronophthisis in two siblings. Clin Exp Nephrol 2005;9:320325.

16 Giridhar S, Padmaraj R, Senguttuvan P: Twins with senior-Loken syndrome. Indian J Pediatr 2006;73:1041-1043.

17 Hildebrandt F: Genetic kidney diseases. Lancet 2010;375:1287-1295.

18 Davis EE, Zhang Q, Liu Q, Diplas BH, Davey LM, Hartley J, Stoetzel C, Szymanska K, Ramaswami G, Logan CV, Muzny DM, Young AC, Wheeler DA, Cruz P, Morgan M, Lewis LR, Cherukuri P, Maskeri B, Hansen NF, Mullikin JC, Blakesley RW, Bouffard GG, NISC Comparative Sequencing Program, Gyapay G, Rieger S, Tönshoff B, Kern I, Soliman NA, Neuhaus TJ, Swoboda KJ, Kayserili H, Gallagher TE, Lewis RA, Bergmann C, Otto EA, Saunier S, Scambler PJ, Beales PL, Gleeson JG, Maher ER, Attié-Bitach T, Dollfus $\mathrm{H}$, Johnson CA, Green ED, Gibbs RA, Hildebrandt F, Pierce EA, Katsanis N: TTC21B contributes both causal and modifying alleles across the ciliopathy spectrum. Nat Genet 2011;43:189-196.
19 Wolf MT, Hildebrandt F: Nephronophthisis. Pediatr Nephrol 2010;26:181-194.

20 Ware SM, Aygun MG, Hildebrandt F: Spectrum of clinical diseases caused by disorders of primary cilia. Proc Am Thorac Soc 2011; 8:444-450.

21 Gascue C, Katsanis N, Badano L: Cystic diseases of the kidney: ciliary dysfunction and cystogenic mechanisms. Pediatr Nephrol 2011;26:1181-1195.

22 Cattran DC, Rao P: Long-term outcome in children and adults with classic focal segmental glomerulosclerosis. Am J Kidney Dis 1998;32:72-79.

23 Mekahli D, Liutkus A, Ranchin B, et al: Long-term outcome of idiopathic steroid-resistant nephrotic syndrome: a multicenter study. Pediatr Nephrol 2009;24:1525-1532.

24 Benoit G, Machuca E, Heidet L, Antignac C: Hereditary kidney diseases: highlighting the importance of classical Mendelian phenotypes. Ann NY Acad Sci 2010;1214:83-98.

25 Heeringa SF, Chernin G, Chaki M, Zhou W, Sloan AJ, Ji Z, Xie LX, Salviati L, Hurd TW, Vega-Warner V, Killen PD, Raphael Y, Ashraf S, Ovunc B, Schoeb DS, McLaughlin HM, Airik R, Vlangos CN, Gbadegesin R, Hinkes B, Saisawat P, Trevisson E, Doimo M, Casarin A, Pertegato V, Giorgi G, Prokisch H, Rötig A, Nürnberg G, Becker C, Wang S, Ozaltin F, Topaloglu R, Bakkaloglu A, Bakkaloglu SA, Müller D, Beissert A, Mir S, Berdeli A, Varpizen S, Zenker M, Matejas V, Santos-Ocaña C, Navas P, Kusakabe T, Kispert A, Akman S, Soliman NA, Krick S, Mundel P, Reiser J, Nürnberg P, Clarke CF, Wiggins RC, Faul C, Hildebrandt F: COQ6 mutations in human patients produce nephrotic syndrome with sensorineural deafness. J Clin Invest 2011;121:2013-2024. 
26 Mele C, Iatropoulos P, Donadelli R, Calabria A, Maranta R, Cassis P, Buelli S, Tomasoni S, Piras R, Krendel M, Bettoni S, Morigi M, Delledonne M, Pecoraro C, Abbate I, Capobianchi MR, Hildebrandt F, Otto E, Schaefer F, Macciardi F, Ozaltin F, Emre S, Ibsirlioglu T, Benigni A, Remuzzi G, Noris M, PodoNet Consortium: MYO1E mutations and childhood familial focal segmental glomerulosclerosis. N Engl J Med 2011;365:295-306.

27 Benoit G, Machuca E, Antignac C: Hereditary nephrotic syndrome: a systematic approach for genetic testing and a review of associated podocyte gene mutations. Pediatr Nephrol 2010;25:1621-1632.
Santín S, Bullich G, Tazón-Vega B, GarcíaMaset R, Giménez I, Silva I, Ruíz P, Ballarín J, Torra R, Ars E: Clinical utility of genetic testing in children and adults with steroidresistant nephrotic syndrome. Clin J Am Soc Nephrol 2011;6:1139-1148.

29 Weins A, Kenlan P, Herbert S, Le TC, Villegas I, Kaplan BS, Appel GB, Pollak MR: Mutational and biological analysis of alpha-actinin-4 in focal segmental glomerulosclerosis. J Am Soc Nephrol 2005;16:3694-3701.
30 Büscher AK, Kranz B, Büscher R, Hildebrandt F, Dworniczak B, Pennekamp P, Kuwertz-Bröking E, Wingen AM, John U, Kemper M, Monnens L, Hoyer PF, Weber S, Konrad M: Immunosuppression and renal outcome in congenital and pediatric steroidresistant nephrotic syndrome. Clin J Am Soc Nephrol 2010;5:2075-2084.

31 Büscher AK, Weber S: Educational paper: the podocytopathies. Eur J Pediatr 2012;DOI 10.1007/s00431-011-1668-2.

\section{Editorial Comment}

Meguid El Nahas, Sheffield, UK

In this minireview, Professor Neveen Soliman from Cairo University highlights the issues related to orphan and rare diseases in nephrology. This is a timely reminder of the challenges facing patients who suffer from orphan diseases as well as their health care providers. Whilst orphan drug development has been at the forefront of renal and nephrology research in the last decade, the cost of such treatment is increasingly prohibitive. Western governments including the USA and EU have supported orphan drug research and development, granting incentives of up to 10 years of exclusivity for manufacturers of such drugs receiving regulatory approval. Consequently, up to 1,500 drug applications have been filed over recent years in the EU alone, with more than 70 drugs being approved in Europe. Also, regulatory bodies have facilitated rapid drug marketing by granting conditional approvals based on limited data and conditional to ongoing monitoring and risk of withdrawal of approval if treatment impact was negative. However, work on orphan drugs could be under threat due to the economic downturn and the exorbitant cost: a single patient with an orphan disease can cost between GBP 100,000 and GBP 400,000 a year! Of note, the anticipated EU expenditure on orphan drugs will reach $4.6 \%$ of total EU pharmaceutical expenditure within the next 5 years. However, due to the economic downturn, Western economies are finding such costs increasingly unaffordable, whilst in emerging economies, such as Egypt, the price of orphan therapies was never affordable. This has encouraged a new brand of activism, bringing patient groups, research- ers and specialists together to facilitate access to health care for orphan disease. Professor Soliman herself has set up EGORD (Egyptian Group for Orphan Renal Disease) with the mission of raising significant funds and increasing awareness for research and treatment of orphan diseases, such as cystinosis. This group, along with other organisations and networks highlighted in this minireview by Professor Soliman, may shift the pharmaceutical industry's attitude to developing and marketing orphan drugs. Whilst some industrialists continue to justify the cost based on years of research and the small market, others, such as Moncef Slaoui, head of research at GSK, recently stated that the industry needs to take a more responsible approach to pricing. It is imperative that pressure is put on the industry to provide affordable care for orphan and rare disease. It is unacceptable that economic downturns impact the health care of those who are sick and most vulnerable in our societies. It is one of the responsibilities of our nephrological community to engage manufacturers of orphan drugs in partnerships to deliver affordable healthcare to those with orphan disease. Such initiatives are nowhere more urgent than in developing countries.

\section{References}

Abbott A: Rare-disease project has global ambitions. Nature 2011;472:17.

2 Simoens S, Cassiman D, Dooms M, Picavet E: Orphan drugs for rare diseases: is it time to revisit their special market access status? Drugs 2012;72:1437-1443. 